\title{
Prospective follow up study of maternal and foetal outcome in abruption placenta
}

\author{
Poovathi M.*, Raji \\ Department of Obstetrics and Gynecology, Thanjavur Medical College, Thanjavur, Tamil Nadu, India
}

Received: 04 April 2016

Accepted: 07 May 2016

\section{*Correspondence:}

Dr. Poovathi M.,

E-mail: drmpoovathi@gmail.com

Copyright: $\odot$ the author(s), publisher and licensee Medip Academy. This is an open-access article distributed under the terms of the Creative Commons Attribution Non-Commercial License, which permits unrestricted non-commercial use, distribution, and reproduction in any medium, provided the original work is properly cited.

\begin{abstract}
Background: Abruptio placentae (AP) which is a major cause of maternal morbidity, mortality and perinatal mortality. Abruptio placentae are one of the leading causes of perinatal deaths. Abruptio placentae increase the neonatal morbidity and mortality. It is one of the recognized causes of low birth weight. The purpose of this study was to examine the risk factors for abruptio placentae together with the maternal and fetal outcome in a tertiary care government medical college hospital.

Methods: All cases of abruptio placentae admitted in the Department of Obstetrics, Government Raja Mirasdar Teaching Hospital, attached to Government Thanjavur Medical College, Tamilnadu, India during the period August 2014 to July 2015 for the period of one year were included in the study. All infants born to those cases were analyzed as live birth or stillbirth. Apgar score and weight of live born infants were also analyzed. Maternal complications such as DIVC, Renal failure, PPH were also analyzed.

Results: The total number of abruptio placentae collected during this period was 102, while the total number of births during the same period was 14620 giving and incidence of $102 / 14620$ ( $0.69 \%$ or 6.9 per thousand live births) for abruptio placentae. The combined stillbirths and first month deaths were $20.2 \%$. Abruptio placentae were associated with pre-eclampsia, diabetes, polyhydramnios and hypertension. Parity and maternal age were not associated with an increased incidence of abruption placentae.

Conclusions: We found an increased risk for abruptio placentae associated with maternal diabetes, hypertension, preeclampsia and polyhydramnios. Abruptio placentae were associated with adverse maternal and foetal outcomes.
\end{abstract}

Keywords: Frequency, Abruptio placentae, Risk factors, Feto-maternal outcomes

\section{INTRODUCTION}

Abruptio placentae is defined as placental detachment before and during delivery. ${ }^{1}$ It occurs in about $0.38-1 \%$ of singleton births, and the incidence increases among twin pregnancies, ranging from 1 to $2 \%^{2,3}$ It is a dangerous obstetric complication associated with an increased risk of foetal and maternal morbidity and mortality. ${ }^{1,4-6}$ Over $50 \%$ of all perinatal deaths attributed to abruptio placentae pregnancies are accompanied by premature delivery. ${ }^{7}$ In addition, abruptio placentae accounts for $20-25 \%$ of antepartum haemorrhages, and it is also associated with an increased risk of disseminated intravascular coagulopathy, severe maternal shock, renal failure, postpartum haemorrhage and maternal death. ${ }^{1,8-10}$ Furthermore, abruptio placentae has been associated with adverse foetal outcomes including low birth weight, preterm birth, intrauterine growth restriction, birth asphyxia, fetal distress, low Apgar score, transfer to neonatal intensive care unit, stillbirth. ${ }^{1,10-12}$

Several risk factors have been associated with abruptio placentae including young or advanced maternal age $(<20$ years or $>=35$ years), previous history of abruptio placentae, previous history of caesarean section, current diabetes mellitus, multiparity (especially grand multiparity), multiple gestations, chronic hypertension, preeclampsia, premature rupture of membranes, 
thrombophilic disorders, and polyhydramnios. ${ }^{4,9,14-21}$ The objective of this study was to determine the frequency, risk factors for abruptio placentae and feto-maternal outcomes associated with abruptio placentae.

\section{METHODS}

This study was conducted in the Department of Obstetrics and Gynaecology, Government Raja Mirasdar Teaching Hospital, attached to Government Thanjavur Medical College, Tamilnadu, India during the period August 2014 to July 2015 for the period of one year. Annually, around 15000 deliveries are conducted at, Government Raja Mirasdar Teaching Hospital, attached to Government Thanjavur Medical College .All women with clinical suspicion of abruption placenta were included in the study. The total numbers of deliveries during the study period were 14,620 .

Detailed history was elicited on mother's and father's socio-demographic factors including occupation, education, age, marital status, alcohol and smoking during pregnancy, body mass index variables (pregnancy and the end of pregnancy). Details on obstetric characteristics as well as medical complications included pre-pregnancy conditions, mother's conditions during pregnancy and after delivery. Information on pregnancy outcome includes child status, still birth, birth weight and gestational age. The duration of hospital stay was calculated as the number of days from admission to the discharge date.

\section{Diagnosis of abruptio placentae}

Diagnosis of abruptio placentae was based on routine clinical examination and ultrasound performed by the attending obstetrician. The diagnosis was based on evidence of retroplacental clot accompanied by clinical features such as vaginal bleeding, abdominal pain, abdominal tenderness, hypertonic uterus and hard abdomen with clinical features of haemorrhage.

All the routine basic investigations, USG, CTG, RFT and Coagulation profile were done. PPH, renal failure and DIVC were analyzed. This study was approved by College Research Ethics Committee, Government Thanjavur Medical College, Tamilnadu, India. The informed consent was obtained from all women included in the study.

\section{Statistical analysis}

Age distribution is shown in table-1.the mean age in our study population was 29.5 years. Women with abruptio placentae had significantly higher mean age as compared to women without abruptio placentae. In our study the age group between $20-25$ years was only $10(9.8 \%)$.

\section{RESULTS}

Table 1: Age of study population $(n=102)$.

\begin{tabular}{|lll|}
\hline Age in years & $n=102$ & $\%$ \\
\hline $20-25$ years & 10 & 9.8 \\
\hline $26-30$ years & 60 & 58.82 \\
\hline $31-35$ years & 20 & 19.6 \\
\hline$>36$ years & 12 & 11.7 \\
\hline
\end{tabular}

Table 2: Parity wise distribution $(\mathrm{n}=102)$.

\begin{tabular}{|lll|}
\hline Gravidity & $\mathrm{n}=\mathbf{1 0 2}$ & $\%$ \\
\hline Primi gravida & 28 & 27.4 \\
\hline Gravida 2 & 38 & 37.2 \\
\hline Gravida 3 & 26 & 25.4 \\
\hline Gravida 4 & 10 & 9.8 \\
\hline
\end{tabular}

In our study, $28(27.4 \%)$ women were primigravidae and 74 were multigravida. Parity wise distribution is shown in Table 2.

Table 3: Pregnancy duration in weeks at presentation.

\begin{tabular}{|lll|}
\hline Gestational age & $\mathrm{n=102}$ & $\%$ \\
\hline$<30$ weeks & 18 & 17.6 \\
\hline $30-36$ Weeks & 42 & 41 \\
\hline$>36$ weeks & 42 & 41 \\
\hline
\end{tabular}

Table 4: Obstetrics risk factors.

\begin{tabular}{|lll|}
\hline Risk factor & $\mathrm{N}=102$ & $\%$ \\
\hline Chronic hypertension & 08 & 7.8 \\
\hline Gestational hypertension & 41 & 40.1 \\
\hline Preeclampsia & 24 & 23.5 \\
\hline eclampsia & 06 & 5.8 \\
\hline Post caesarean pregnancy & 05 & 4.9 \\
\hline polyhydramnios & 04 & 3.9 \\
\hline PROM & 03 & 2.9 \\
\hline Multiple pregnancy & 02 & 1.9 \\
\hline idiopathic & 07 & 6.8 \\
\hline Recurrent abruption & 01 & 0.9 \\
\hline Short cord & 01 & 0.9 \\
\hline
\end{tabular}

A total of 14,620 deliveries were analyzed. The incidence of abruptio placentae during the study period was $0.69 \%$ $(102 / 14,620)$. Demographic and obstetric characteristics of the participants are described in Table I. Women with abruptio placentae had significantly higher mean age as compared to women without abruptio placentae, (29.5) Those who residing in rural areas and low socioeconomic were all at increased risk for abruptio placentae. Furthermore, the proportion of abruption increased with high parity, although an association with maternal smoking and alcohol consumption during pregnancy was not attributable since none of them in the study group were smoking and alcohol consumption. 
Demographic and obstetric characteristics of the study participants

\section{Risk factors for abruptio placentae}

Risk factors associated with abruptio placentae are summarized in Table 4. The risk factors of abruptio placentae in this population were chronic hypertension among 08 women (7.8\%) gestation hypertension was diagnosed in 41 women $(40.1 \%)$, preeclampsia were 24 $(23.5 \%)$ and eclampsia were $6(5.8 \%)$. Prior caesarean section delivery were $5(4.9 \%)$ complicated by abruption Other known risk factors for abruptio placentae such as multiple gestations and male infant gender were not significantly associated with abruptio placentae in this population.

Maternal and foetal outcomes are associated with degrees of severity of placental abruption.

\section{Degrees of severity of placental abruption}

Mild (grade 1): This is not recognized clinically before delivery and usually diagnosed by the presence of a retroplacental clot. This is a retrospective diagnosis.

Moderate (grade 2): This is an intermediate grade in which the classical clinical signs of abruption are present but the fetusis still alive. The frequency of fetal heart abnormalities is high.

Severe (grade 3): This is the severe grade in which the fetus is dead and coagulopathy may be present. The volume of blood loss is appreciable in this condition.

\section{Table 5: Maternal outcome associated with Abruptio} placenta.

\begin{tabular}{|lll|}
\hline Antepartum haemorrhage & $\mathrm{n}=\mathbf{1 0 2}$ & $\%$ \\
\hline Concealed haemorrhage & 78 & 76.4 \\
\hline Acute renal failure & 14 & 13.7 \\
\hline Postpartum haemorrhage & 5 & 4.7 \\
\hline $\begin{array}{l}\text { Disseminated intravascular } \\
\text { coagulation }\end{array}$ & 10 & 9.8 \\
\hline Caesarean delivery & 8 & 7.8 \\
\hline hysterectomy & 82 & 80.3 \\
\hline Maternal death & 2 & 1.9 \\
\hline
\end{tabular}

\section{Maternal outcomes associated with abruptio placentae}

Maternal outcomes associated with abruptio placentae are illustrated in Table 5. In our study it is observed that 78 (76.4\%) had antepartum haemorrhage, 14 (13.7) women had concealed haemorrhage. $5(4.7 \%)$ had acute renal failure. $10(9.8 \%)$ women had postpartum haemorrhage and $8(7.8 \%)$ had disseminated intravascular coagulation. Caesarean section delivery needed in 82 (80.3\%).
Hysterectomy done for two women (1.9\%) who had atonic PPH not responding to conservative medical and surgical measures. There were two maternal deaths $(1.9 \%)$ in our study which were related to disseminate intravascular coagulation and hypoxic ischemic encephalopathy. Similarly, women with abruptio placentae were more likely to have prolonged hospital stay. Moreover, patients with abruptio placentae had increased need for being transferred to intensive care unit, but the association did not reach statistical significance.

Table 6: Fetal outcomes associated with abruptio placentae.

\begin{tabular}{|lll|}
\hline Fetal outcome & Number of patients n & $\%$ \\
\hline Live babies & 60 & 58.8 \\
\hline Still born & 42 & 41.1 \\
\hline
\end{tabular}

The foetal outcomes associated with abruptio placentae have been summarized in Table VII. After infants born to women with abruptio placentae had increased risk of low birth weight, perinatal death, early neonatal death and stillbirth especially fresh stillbirth. In addition, infants born to women with abruptio placentae had increased risk of low Apgar scores (below 7) at 1st and 5th min. The association between abruptio placentae with preterm birth and fetal distress was not statistically significant. Overall, abruptio placentae contributed to perinatal mortality rate of 2.8 per 1000 births $40 / 14620$ ).

\section{DISCUSSION}

In this study, we found that the incidence of abruptio placentae was $0.69 \%$. The risk factors for abruptio placentae were chronic hypertension, preeclampsia/eclampsia, previous caesarean delivery or abruptio placentae, poor attendance to antenatal care and high parity. Patients with abruptio placentae had increased risk of adverse maternal and foetal outcomes. Post-partum haemorrhage was an important predictor maternal death.

\section{Comparison with previous studies}

The incidence of abruptio placentae in our study corresponds with incidence of $0.69 \%$ which has been reported previously. ${ }^{18}$ This figure also falls within the range of $0.3-2 \%$, reported by others, but it is lower than what has been reported previously in Uganda and Israel. ${ }^{2,3,8,13,22,23}$ The difference in incidence could partly be explained by the differences in the studied populations, study designs and diagnostic criteria.

Previous studies reported the association between increased risk of abruptio placentae with chronic hypertension and preeclampsia/eclampsia. ${ }^{15,19,21,22,24-29}$ Our results are in general agreement with previous reports. 
Previous studies reported the association between previous caesarean delivery and increased risk of abruptio placentae. The risk of abruptio placentae increased by nearly 2-fold for women with prior caesarean section delivery. Similar observation was reported elsewhere. ${ }^{18-20,30}$ In contrast the association with previous caesarean delivery is less in our study $4.9 \%$. The increased risk of abruption among women with prior caesarean delivery may imply that these women had ruptured scar from the previous caesarean. The differences in risk of abruption placentae between our study and those of others may be explained by the differences in pre-existing conditions which are associated with abruptio placentae between the studied populations.

Abruptio placentae in a previous pregnancy are an important risk factor for abruptio placentae in subsequent pregnancies, which is not in correlation in our study. ${ }^{32}$ An association between prior abruptio placentae and its recurrence in the subsequent pregnancies was demonstrated by Rasmussen and colleagues in a Norwegian cohort were they reported a 5-fold increase in relative recurrence risk of abruptio placentae. ${ }^{33}$ This indicates that more persistent risk factors such as preeclampsia and chronic hypertension.

In the present study, the occurrence of abruptio placentae was higher in women with high parity and multigravida as compared to nulliparous or primigravida women. These results are in line with many previous studies. $^{24,25,34-38}$ Previous studies have reported that both maternal cigarette smoking and alcohol consumption during pregnancy are associated with abruptio

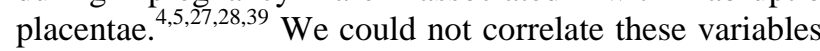
in our study since there were no smokers and alcoholics in our study.

The occurrence of abruptio placentae has been associated with an increased risk of maternal and foetal morbidity and mortality in previous studies. ${ }^{1,3,6,22}$ Pregnancy with severe haemorrhage may be more likely to be recorded as abruptio placentae if the baby dies.

The observed maternal death rate $1.9 \%$ related to abruptio placentae in our study is above the maximum acceptable rate of $1 \% .^{7}$ In our study, women with pregnancies complicated by abruptio placentae had sixfold risk of delivering an infant with low birth weight . Similar finding was reported in Uganda. ${ }^{22}$ The high risk of low birth weight delivery among women with abruptio placentae may be explained by the effect of preterm birth due to premature termination of pregnancy performed by clinicians due to severity of abruptio placentae or effect of intrauterine foetal growth retardation. The risks of stillbirth, early neonatal death and perinatal death were also higher among women with abruptio placentae as compared to women without abruptio. These results are in consistent with previous studies. ${ }^{1,6,9,13,21,23}$ It has been previously reported that the magnitude of stillbirth is dependent on the degree of separation of placentae, particularly when it exceeds $50 \% .^{12}$ This could be the case for some women in the present study, which in turn could be the reason for the observed high risk of perinatal death and its components. However, the observed excess risk in perinatal death may also likely to be caused by prematurity and intrauterine foetal growth restriction. It is worth noting that the perinatal mortality rate observed in our study is 2.8 per 1000 deliveries reported elsewhere. ${ }^{6}$

Furthermore, patients with abruptio placentae were more likely to deliver a baby with low Apgar score at $1^{\text {st }}$ and $5^{\text {th }}$ minutes respectively. The high risk of low Apgar score may be due to prematurity.

\section{CONCLUSION}

Our study confirmed that chronic hypertension, preeclampsia/eclampsia, previous caesarean delivery or abruptio placentae and high parity are independent risk factors for abruptio placentae. Abruptio placentae are associated with adverse maternal and fetal outcomes. Our results provide clinicians with important information to consider when counselling women during prenatal care about the risk factors for abruptio placentae, early identification of women at risk of abruptio placentae and develop individual follow up plan with specific intervention. Improved attendance to antenatal care and timely management of these factors may reduce the risk of abruptio placentae and associated adverse fetomaternal outcomes. Furthermore, better equipped obstetric and neonatal units to improve both maternal and perinatal outcomes in this setting are warranted.

\section{ACKNOWLEDGEMENTS}

I gratefully acknowledge and express my sincere thanks to our Dean, Thanjavur Medical College and hospital, Thanjavur, India for allowing me to do this study and utilizing the Institutional facilities. I would also like to thank all the medical and para-medical staffs who have helped me complete this study. A special thanks to all the patients who willingly co-operated and participated in this study. I would like to thank all my colleagues and friends who have been a constant source of encouragement to me. My co- author Dr. Raji read and approved the final manuscript.

Funding: No funding sources

Conflict of interest: None declared

Ethical approval: The study was approved by the Institutional Ethics Committee

\section{REFERENCES}

1. Tikkanen M. Placental abruption: epidemiology, risk factors and consequences. Acta Obstet Gynecol Scand. 2011;90(2):140-9.

2. Ananth CV, Getahun D, Peltier MR, Smulian JC. Placental abruption in term and preterm gestations: 
evidence for heterogeneity in clinical pathways. Obstet Gynecol. 2006;107(4):785-92.

3. Ananth CV, Wilcox AJ. Placental abruption and perinatal mortality in the United States. AJE. 2001;153(4):332-7.

4. Ananth CV, Cnattingius S. Influence of maternal smoking on placental abruption in successive pregnancies: a population-based prospective cohort study in Sweden. AJE. 2007;166(3):289-95.

5. Rasmussen S, Irgens L, Dalaker K. The effect on the likelihood of further pregnancy of placental abruption and the rate of its recurrence. Br J Obstet Gynaecol. 1997;104(11):1292-5.

6. Bibi S, Ghaffar S, Pir MA, Yousfan S. Risk factors and clinical outcome of placental abruption: a retrospective analysis. JPMA. 2009;59(10):672-4.

7. Carr SR. High risk pregnancy: management options. JAMA. 1995;273(3):259-60.

8. Hall DR. Abruptio placentae and disseminated intravascular coagulopathy. Semin Perinatol. 2009;33(3):189-95.

9. Jabeen M, Gul F. Abruptio placentae: risk factors and perinatal outcome. J Postgrade Med Inst. 2011;18(4):669-76.

10. Sarwar I, Abbas A, Islam A. Abruptio placentae and its complication at Ayub Teaching Hospital Abbotabad. J Ayub Med Coll Abbottabad. 2006;18(1):27-31.

11. Jakobsson M, Gissler M, Paavonen J, Tapper AM. The incidence of preterm deliveries decreases in Finland. BJOG. 2008;115(1):38-43.

12. Morgan K, Arulkumaran S. Antepartum haemorrhage. Curr Obstet Gynaecol. 2003;13(2):817.

13. Salihu HM, Bekan B, Aliyu MH, Rouse DJ, Kirby RS, Alexander GR. Perinatal mortality associated with abruptio placenta in singletons and multiples. Am J Obstet Gynecol. 2005;193(1):198-203.

14. Nath CA, Ananth CV, Smulian JC, Shen-Schwarz S, Kaminsky L. Histologic evidence of inflammation and risk of placental abruption. Am J Obstet Gynecol. 2007;197(3):319.e311-9.

15. Kyrklund-Blomberg NB, Gennser G, Cnattingius S. Placental abruption and perinatal death. Paediatr Perinat Epidemiol. 2001;15(3):290-7.

16. Rasmussen S. Abruptio placentae - relationship with other placental dysfunction related conditions. Norsk Epidemiologi. 2007;17(2):191-7.

17. Sanchez SE, Williams MA, Pacora PN, Ananth CV, Qiu C, Aurora SK, Sorensen TK. Risk of placental abruption in relation to migraines and headaches. BMC Womens Health. 2010;10:30.

18. Getahun G, Oyelese Y, Salihu HM, Ananth CV. Previous Cesarean delivery and risks of placenta previa and placental abruption. Obstet Gynecol. 2006;107(4):771-8.

19. Rasmussen S, Irgens LM, Dalaker K. A history of placental dysfunction and risk of placental abruption. Paediatr Perinat Epidemiol. 1999;13(1):9-21.
20. Lydon-Rochelle M, Holt VL, Easterling TR, Martin DP. First-birth cesarean and placental abruption or previa at second birth. Obstet Gynecol. 2001;97(5):765-9.

21. Sanchez SE, Pacora PN, Farfan JH, Fernandez A, Qiu C, Ananth CV, Williams MA. Risk factors of abruptio placentae among Peruvian women. Am J Obstet Gynecol. 2006;194(1):225-30.

22. Wandabwa J, Doyle P, Kiondo P, Margaret A, Wandabwa A, Aziga F. Risk factors for severe abruptio placenta in Mulago Hospital, Kampala, Uganda. Afr Health Sc. 2005;5(4):285-90.

23. Sheiner E, Shoham-Vardi I, Hallak M, Hadar A, Gortzak-Uzan L, Katz M, Mazor M. Placental abruption in term pregnancies: clinical significance and obstetric risk factors. J Matern Fetal Neonatal Med. 2003;13(1):45-9.

24. Ananth CV, Wilcox AJ, Savitz DA, Bowez WA, Jr, Luther ER. Effects of maternal age and parity on the risk of uteroplacental bleeding disorders of pregnancy. Obstet Gynecol. 1996;88:511-6.

25. Williams MA, Lieberman E, Mittendorf R, Monson RR, Schoenbaum SC. Risk factors for abruptio placentae. Am J Epidemiol. 1991;134:965-72.

26. Kramer MS, Usher RH, Polllack R, Boyd M, Usher S. Etiologic determinants of abruptio placentae. Obstet Gynecol. 1997;89:221-6.

27. Hung TH, Hsieh CC, Hsu JJ, Lo LM, Chiu TH, Hsieh TT. Risk factors for placental abruption in an Asian population. Reprod Sci J. 2007;14(1):59-65.

28. Tikkanen M, Nuutila M, Hiilesmaa V, Paavonen J, Ylikorkala O. Prepregnancy risk factors for placental abruption. Acta Obstet Gynecol Scand. 2006;85(1):40-4.

29. Tikkanen M, Nuutila M, Hiilesmaa V, Paavonen J, Ylikorkala O. Clinical presentation and risk factors of placental abruption. Acta Obstet Gynecol Scand. 2006;85(6):700-5.

30. Rageth JC, Juzi C, Grossenbacher H. Delivery after previous cesarean: a risk evaluation. Swiss Working Group of Obstetric and Gynecologic Institutions. Obstet Gynecol. 1999;93(3):332-7.

31. Nayama M, Tamakloé-Azamesu D, Garba M, Idi N, Djibril B, Kamayé M. Abruptio placentae. Management in a reference Nigerien maternity. Prospective study about 118 cases during one year. Gynecol Obstet Fertil. 2007;35(10):975-81.

32. Cunningham GF, MacDonald PC, Gant NF, et al. Williams obstetrics. 19. Norwalk: Appleton \& Lange; 1993. eds, chapter 37. Obstetric hemorrhage; pp. 819-851.

33. Rasmussen S, Irgens LM, Albrechtsen S, Dalaker K. Women with a history of placental abruption: when in subsequent pregnancy should special surveillance for a recurrent placental abruption be initiate? Acta Obstet Gynecol Scand. 2001;80(8):708-12.

34. Abu-Heija A, Al-Chalabi H, El-lloubani N. Abruptio placentae: risk factors and perinatal outcome. J Obstet Gynaecol Res. 1998;24(2):141-4. 
35. Hossain NKN, Sultana SS, Khan N. Abruptio placenta and adverse pregnancy outcome. J Pak Med Assoc. 2010;60(6):443-6.

36. Thieba B, Lankoande J, Akotionga M, Kyelem C, Ouedraogo A, Ouedraogo CM. Abruptio placentae: epidemiological, clinical and prognostic aspects with respect to a 177 case series. Gynecol Obstet Fertil. 2003;31(5):429-33.

37. Ananth CV, Peedicayil A, Savitz DA. Effect of hypertensive diseases in pregnancy on birthweight, gestational duration, and small-or-gestational-age births. Epidemiology. 1995;6(4):391-5.

38. Saeed M, Rana T. Fetomaternal outcome in pregnancies complicated with placental abruption. PJMH. 2011;5(1):1-5.

39. Du Toit MM, Smith M, Odendaal HJ. The role of prenatal alcohol exposure in abruptio placentae. S Afr Med J. 2010;100(12):832-5.

Cite this article as: Poovathi M, Raji. Prospective follow up study of maternal and foetal outcome in abruption placenta. Int J Reprod Contracept Obstet Gynecol 2016;5:1784-9. 